\title{
La guerra fría en las favelas y las poblaciones, 1945-1964. Una disputa entre comunistas e Iglesia Católica*
}

The cold war in the favelas and the poblaciones, 1945-1964. A conflict between communists and the Catholic Church.

\author{
Emanuel Giannotti** \\ Rafael Soares Gonçalves ${ }^{* * *}$
}

Resumen: Las "favelas" de Río de Janeiro y las "poblaciones" de Santiago de Chile recibieron habitualmente las visitas de actores externos. Muchas veces conocemos las historias de estos lugares gracias a los relatos de trabajadoras sociales, estudiantes, militantes políticos o benefactores. Con el inicio de la guerra fría la presencia de estos actores asumió un nuevo significado, siendo muy importante la disputa entre comunistas e Iglesia Católica, que se contendieron la hegemonía del espacio popular, a veces llegando a enfrentamientos violentos. Sin embargo, las actividades desarrolladas por estas instituciones permitieron fortalecer la organización de los habitantes y aportar mejoras a sus barrios, contribuyendo a una mayor integración urbana, social y política.

palabras clave: favelas, Río de Janeiro, poblaciones, Santiago de Chile, Iglesia Católica, Partido Comunista

\begin{abstract}
The "favelas" of Rio de Janeiro and the "poblaciones" of Santiago de Chile were usually visited by external actors. It is through the accounts of social workers, students, political activists or volunteers that we know about the histories of these places. With the beginning of the cold war, the presence of these individuals took on a new meaning. In this backdrop, the conflict between the communists and the Catholic Church for the hegemony over the low-income neighborhoods, which sometimes led to violent confrontations, took a central stage. Yet, the activities developed by these institutions strengthened the organization of the inhabitants and physically improved these neighborhoods, fostering their urban, social and political integration.
\end{abstract}

Keywords: favelas, Rio de Janeiro, poblaciones, Santiago de Chile, Catholic Church, Communist Party

Recibido: 2 noviembre 2018 Aceptado: 16 enero 2019

\footnotetext{
* Este artículo es un resultado de una investigación financiada por el proyecto Fondecyt de iniciación no 11150589 (Chile) y Jovem Cientista do Nosso Estado (FAPERJ/Brasil) y Produtividade em pesquisa (CNPQ/Brasil). Agradecemos igualmente el apoyo del proyecto La ville informelle an XX siècle, financiado por la Mairie de Paris.

** Italiano, profesor asistente, Facultad de Arquitectura y Urbanismo, Universidad de Chile, egiannotti@uchilefau.cl

${ }^{* * *}$ Brasileño, profesor asociado, Departamento de Trabajo Social, Pontificia Universidad Católica de Río de Janeiro (PUC-

Río), rafaelsgoncalves@yahoo.com.br
} 


\section{Introducción}

En un estudio de los primeros años setenta, se destacaba "una situación muy curiosa en las barriadas de Lima: los invasores han resultado invadidos." Una multitud de instituciones privadas, en la mayoría de orientación católica o financiadas por EE.UU., estaban realizando un extenso trabajo, movilizando "muchedumbres de "voluntarios", "misioneros", "agentes", "promotores", "científicos sociales", "encuestadores", "asistentes sociales", etc.". ${ }^{1}$ La tesis de los autores, era que estas instituciones tenían como objetivo la desmovilización política de los pobladores. Sin embargo, alertaban sobre el riesgo de extender estas conclusiones a otros países, para los cuales era necesario considerar el contexto político, señalando que, en otros casos, como el chileno, podía existir un potencial revolucionario.

En los mismos años, en Chile, el "equipo de estudios poblacionales CIDU", ${ }^{2}$ liderado por Manuel Castells, estaba investigando los "campamentos", preguntándose si en estos lugares se estaban experimentado innovaciones sociales que podían crear un poder popular. Los primeros escritos del equipo estaban teñidos por un cierto optimismo al respecto. Si bien se señalaban varias criticidades, los campamentos eran descritos como "una experiencia de lucha política y un desafío al antiguo orden urbano". 3 Sin embargo, unos años después, Castells volvió sobre el tema con tonos más escépticos, sosteniendo que en esa experiencia de revolucionario no hubo tanto, que las innovaciones sociales fueron limitadas, y que se trató más bien de proselitismo político. ${ }^{4}$

La participación y orientación política de los barrios populares fue un tema muy discutido y estudiado. ${ }^{5}$ Varios estudios de la segunda mitad de los años sesenta y de los primeros años setenta, coincidieron en que, una vez obtenido un terreno propio y un techo, las actitudes de los habitantes de estos barrios eran más bien conservadoras, prevaleciendo un deseo de integración en las sociedades nacionales. ${ }^{6}$ Desde la perspectiva actual, podemos aseverar que efectivamente los barrios populares no se transformaron en focos revolucionarios. El tema ha desaparecido de las investigaciones recientes, que,

\footnotetext{
1 Alfredo Rodríguez, Gustavo Riofrío, Eileen Welsh “De invasores a invadidos” Revista EURE, 2:4, 1972, pp. 101-142. El estudio se inició a mediados de 1969 y fue publicado en Cuadernos DESCO, noviembre de 1971, Lima

2 El Centro Interdisciplinario de Desarrollo Urbano (CIDU), se creó a mitad de los años sesenta en la Universidad Católica de Chile, gracias a un financiamiento de la Fundación Ford.

3 Manuel Castells, 1974, Movimientos sociales urbanos, Siglo XXI. Entre 1971 y 1973, el equipo publicó varios artículos en los primeros números de la revista EURE, en particular el $\mathrm{n}^{\circ} 7$.

${ }_{4}^{4}$ Manuel Castells, The city and the grassroots. A cross-cultural theory of urban social movements, Berkley and Los Angeles, University of California, 1983

5 Para una síntesis, véase: Howard Handelman, “The political mobilization of urban squatter settlements. Santiago’s recent experience and its implications for urban research", Latin American Research Review, 10:2, pp. 35-72. Alexis Cortés, "A Struggle Larger Than a House: Pobladores and Favelados in Latin American Social Theory". In Latin American Perspectives, 40:2, 2013, p. 168-184.

${ }^{6}$ Daniel Goldrich, Raymond Pratt, C. R. Schuller, "The political integration of Lower-Class Urban Settlements in Chile and Peru", Studies in Comparative International Development, 3:1, 1967, pp. 3-22. Luis A. Machado da Silva, "A política na Favela", Cadernos Brasileiros, $\mathrm{n}^{\circ}$ 41, 1967, p.35-47. John Turner, "Uncontroled urban settlement: Problems and Policies", International Social Development Review, 1, 1968, pp. 107-130. Stephen Conn, "The squatters' rights of favelados", Ciências Econômicas e Sociais, n², 1968, p.50-142. Wayne Cornelius, "Urbanization as an agent in Latin American Political Instability: The Case of Mexico", American Political Science Review, 63:3, 1969, pp. 833-857. Anthony Leeds, Elizabeth Leeds, A sociología do Brasil urbano. Zahar editores, 1978. Carlos Nelson F. dos Santos, Três movimentos sociais urbanos no Río de Janeiro. Tésis de maestria, Museu Nacional/UFRJ, 1979. El tema no se estaba estudiando solamente en referencia a Latinoamérica. Ver, por ejemplo: Joan Nelson, "The urban poor. Disruption or political integration in Third World Cities?", World Politics, 22-3, pp. 393-414.
} 
más bien, han sido dedicadas a la segregación social generadas por las políticas públicas, ${ }^{7}$ a la persistencia del fenómeno del clientelismo, ${ }^{8} \mathrm{o}$ a la proliferación de la violencia y del narcotráfico. ${ }^{9}$

Sin embargo, en los años cuarenta, cincuenta y sesenta, las autoridades estaban seriamente preocupadas de la amenaza comunista, la cual se estaba infiltrando en los barrios populares, formando cinturones rojos alrededor de las metrópolis latinoamericanas. Esto no era nuevo, pero estaba asumiendo un nuevo significado en un contexto internacional marcado por el inicio de la guerra fría, cuyas claras delimitaciones ideológicas influenciaron también los actores que operaban en las "barriadas", las "favelas", las "poblaciones" y las "villas miseria".

Comúnmente, estos lugares urbanos han sido estudiados de manera aislada, siendo bastante escasos los estudios comparativos. ${ }^{10}$ En el presente artículo se considerarán dos casos, las "favelas" de Río de Janeiro y las "poblaciones" de Santiago de Chile, 11 durante un periodo que va desde el inicio de la guerra fría, al golpe de Estado en Brasil. En estos países, las jerarquías católicas fueron importante para la renovación de la iglesia latinoamericana de esos años, así como los Partidos Comunistas jugaron un papel importante, a pesar de ser proscritos a final de los años cuarenta. Además, Río y Santiago ofrecen un amplio conjunto de experiencias, significativas para la comprensión de los pobres urbanos en América Latina, como afirma Alexis Cortés. ${ }^{12}$

Recurriendo a periódicos, archivos públicos y privados, se analizará el rol que tuvieron la Iglesia Católica y el Partido Comunista en los procesos de formación, consolidación e integración de favelas y poblaciones. Existen varios estudios que muestran como estos barrios, más que espontáneos, se originaron y crecieron en estricta relación con los procesos urbanos, políticos, económicos y normativos que interesaron la sociedad entera. ${ }^{13}$ Esta densa capa de relaciones se puede investigar observando, entre otras cosas, los varios actores presentes en los asentamientos populares y las acciones que estos pusieron en marcha, clarificando las convergencias y los conflictos entre distintos objetivos, intereses e ideologías.

$\mathrm{Al}$ respecto, hay que recordar, en primer lugar, que los actores presentes en los barrios populares eran variados y heterogéneos. ${ }^{14}$ Había varias confesiones religiosas, en particular los protestantes. ${ }^{15}$ Había voluntarios extranjeros, como aquellos del Cuerpo de Paz de Estados Unidos, que fueron enviados en todos los países de América Latina durante la década de 1960, y que a veces contribuyeron a desarrollar

\footnotetext{
${ }^{7}$ Manuel Tironi, Nueva pobreza urbana. Vivienda y capital social en Santiago de Cbile, 1985-2001, Santiago, Universidad de Chile y RIL editores, 2003. Alfredo Rodríguez, Ana Sugranyes, Los con techo. Un desafio para la política de vivienda social, Santiago, Ediciones SUR, 2005.

${ }^{8}$ Javier Auyero, La política de los pobres. Las prácticas clientelistas del peronismo. Buenos Aires, Manatial, 2001

9 Luiz Antonio Machado da Silva, "Violência urbana", segurança pública e favelas - o caso do Río de Janeiro atual", Caderno CRH, 23:59, 2010. Rosinaldo Silva de Sousa, "Narcotráfico y economía ilícita: las redes de crimen organizado en Río de Janeiro", Revista mexicana de sociologia, 66:1, 2004

10 Algunas excepciones: Leandro Benmergui, "The Alliance for Progress and Housing Policy in Rio de Janeiro and Buenos Aires in the 1960s." Urban History, 36:2, 2009, p.303-326. Óscar Calvo, Urbanización y revolución. Técnica y politica en Santiago de Chile, Buenos Airesy Ciudad de México (1950-1980), Tesis de Doctorado en Historia, Colegio de México, 2013. Alexis Cortés, Favelados epobladores nas Ciências Sociais: a construção teórica de um movimento social, Rio de Janeiro, Ed.UERJ, 2018.

11 Con el término "población", en Chile se identifica un conjunto habitacional. Si bien comenzó a ser utilizado para conjuntos de clase medio-alta, bastante rápidamente pasó a estar asociado a los sectores populares.

12 Cortés, Favelados e pobladores... op. cit., p.24.

13 Para el caso de Río véanse los trabajos de Lícia Valladares, Brodwyn Fischer, Rafael Soares Gonçalves, Mauro Amoroso, Mário Brum, Marcos Pestana, Rafael de Almeida. Para el caso de Santiago, los trabajos de Vicente Espinoza, Mario Garcés, Emanuel Giannotti, Boris Cofré, Alexis Cortés, Edward Murphy.

${ }^{14}$ Esto ha sido destacado por varios estudios. Por el caso chileno: Manuel Castells, "Movimiento de pobladores y lucha de clases en Chile", in EURE, 3:7, 1972, pp. 9-35. Vicente Espinoza, "Historia social de la acción colectiva urbana: los pobladores de Santiago 1957-1987', in EURE, 24:72, 1998, pp. 71-84.

15 Jean Pierre Bastian, Protestantismos y modernidad latinoamericana. Historia de unas minorías religiosas en América Latina, Fondo de Cultura Económica, 2013; Carlos Alberto Medina y Licia Valladares, Favela e religião: um estudo de caso (inserção e socialização de crianças e jovens nas atividades religiosas católicas), Río de Janeiro: CNBB, 1968.
} 
investigaciones académicas y proyectos sociales en los barrios populares. ${ }^{16}$ Otras veces, la cooperación internacional pasaba a través del financiamiento de organizaciones de beneficencia, como aquellas católicas, las cuales también eran muy presentes en estos barrios. Había militantes de diversos partidos, que entrelazaban relaciones con diputados, funcionarios públicos, autoridades municipales y nacionales, los cuales también visitaban estos lugares. ${ }^{17}$ En esta heterogeneidad, y excluyendo los organismos del Estado, los casos de estudios muestran que la Iglesia Católica y el Partido Comunista fueron las instituciones cuya presencia y actividades fueron las más profusas y organizadas, en el periodo considerado. Además, es necesario puntualizar que los habitantes de las favelas y de las poblaciones no recibieron estos actores de manera pasiva. Si bien el nivel de participación era muy diverso, los habitantes estaban directamente involucrados con estas instituciones, a menudo integrando sus estructuras y muchas veces buscando su apoyo. A pesar que por simplicidad hablamos de habitantes o pobladores, por un lado, y de actores externos o benefactores por el otro, los límites entre los dos eran muy fluido.

En segundo lugar, no se puede desconocer que, en el periodo considerado, las actividades de católicos y comunistas tenían un claro sentido político, que llevó a disputarse la hegemonía del espacio popular, a veces llegando a enfrentamientos violentos. Las favelas y las poblaciones se transformaron en un terreno de lucha ideológica y electoral. Si esto puede haber incentivado el proselitismo y las relaciones clientelares, significó también la adquisición de un peso político por parte de los habitantes. Además, las actividades desarrolladas tanto por los comunistas como por los católicos, permitieron fortalecer la organización de los habitantes, contribuyendo a una mayor integración social y política. Estas actividades se desarrollaron muchas veces alrededores de trabajos de mejoras urbanísticas, que consolidaron los barrios y facilitaron el proceso de inserción en el tejido urbano. ${ }^{18}$

En tercer lugar, es importante remarcar que los dos casos tienen importantes diferencias, pero también varias similitudes. Efectivamente, las favelas de Río y las poblaciones de Santiago fueron dos fenómenos sociales y urbanos con características bastantes distintas, por temporalidades, tamaño, y actores involucrados. Sin embargo, ambas estuvieron caracterizadas por las condiciones de precariedad, material y de tenencia, que orientaron las luchas de los favelados y de los pobladores hacia una demanda de estabilidad y permanencia. En el caso de las favelas, este deseo se expresó en una lucha contra las amenazas de desalojo. ${ }^{19}$ En el caso de las poblaciones, en los años cuarenta se pueden observar dinámicas similares, las cuales, en la década siguiente, se transformaron en la reivindicación de un lugar propio a través de "tomas" de terreno. ${ }^{20}$

\footnotetext{
${ }^{16}$ Fernando Purcell, "Connecting Realities: Peace Corps Volunteers in South America and the Global War on Poverty during the 1960s", Historia Critica $\mathrm{n}^{\circ}$ 53, 2014; Id. "Guerra fría, motivaciones y espacios de interacción. El caso del cuerpo de paz de Estados Unidos en Chile, 1961-1970”, en Tanya Harmer and Alfredo Riquelme, eds., Chile y la guerra fría global, Ril editores, 2014. Cecilia Azevedo, Em nome da América: os Corpos da Paz no Brasil, Alameda, 2008. Fernando Purcell, Marcelo Casals, "Espacio en disputa: el Cuerpo de Paz y las universidades sudamericanas durante la Guerra Fría en la década de 1960", História Unisinos, 19:1, 2015. .Lícia Valladares, "Le langage de la coopération internationale Peace Corps et ONGs dans les favelas à Río de Janeiro", en Daniel Cefai y Isaac Joseph, L'béritage du pragmatiste. Conflits d'urbanité et épreuves de civisme. Paris, Éditions de 1'Aube, 2002.

${ }_{17}$ Con respecto a la presencia de militantes políticos, muy peculiar fue el caso chileno, que fue ampliamente investigado durante los primeros años setenta. Véase: Joaquín Duque y Ernesto Pastrana, "La movilización reivindicativa urbana de los sectores populares en Chile: 1964-1972" Revista Latinoamericana de Ciencias Sociales, 4, pp. 259-293; Manuel Castells, "Movimiento de pobladores y lucha de clases en Chile", Revista EURE, 3:7, 1973, pp. 9-35.

18 Para el caso chileno, véase: Manuel Loyola, Los pobladores de Santiago; 1952-1964: su fase de incorporación a la vida nacional, Tesis para optar al grado de licenciatura en Historia, Pontificia Universidad Católica de Chile, Santiago, 1989. Para el caso de Rio de Janeiro, véase: Nísia Trindade Lima, O movimento de favelados do Rio de Janeiro. Políticas do Estado e lutas sociais (1954-1973). Tesis de maestria en ciências políticas, IUPERJ/Universidade Cândido Mendes, Rio de Janeiro, 1989.

${ }_{19}$ Rafael Soares Gonçalves, Favelas de Rio de Janeiro. Historia y derecho, Ediciones Javeriana, Bogotá, 2018; Marco Pestana, A União dos Trabalhadores Favelados e a luta contra o controle negociado das favelas cariocas (1954-1964), Niterói: Eduff, 2016; Maria Lais Pereira da Silva, Favelas Cariocas (1930-1964), Rio de Janeiro: Contraponto Editora, 2005.

${ }^{20}$ Vicente Espinoza, Para una historia de los pobres de la ciudad, Santiago, SUR, 1988. Armando De Ramón, "La población informal. Poblamiento de la periferia de Santiago de Chile, 1920-1970”, en EURE, 16: 50, 1990, pp. 5-17
} 
Con respecto a la situación internacional, en ambos países el Partido Comunista fue proscripto poco después del planteamiento de la doctrina Truman en 1947. Sin embargo, en Chile la proscripción duró una década, volviendo el Partido Comunista a participar en las elecciones de 1958, en una coalición de izquierda; mientras en Brasil, el Partido Comunista permaneció en la clandestinidad hasta el final de la dictadura, aunque ejerció una fuerte influencia política y mantuvo una relación problemática de acercamiento y alejamiento con los laboristas, que tuvieron el poder hasta el golpe militar de 1964. En ambos países, durante la proscripción, era una práctica común que los militantes comunistas usasen otros partidos para ser elegidos. ${ }^{21}$

Por otro lado, las autoridades eclesiales contribuyeron de manera determinante a la renovación de las Iglesias de los dos países, a un nivel nacional y latinoamericano, pero en Chile estas innovaciones se articularon con un importante partido católico, creado en 1957 y que llegó al poder en la segunda mitad de los años sesenta. ${ }^{22}$ Las tendencias progresistas fueron empujadas por la creación, en 1955, de la Conferencia Episcopal Latinoamericana (CELAM), promovida por figuras como Hélder Camara y Manuel Larraín, obispos de Río y de Talca. Una definitiva legitimación llegó con el anuncio, en 1959, del Concilio Vaticano II. Sucesivamente, la opción para los pobres llevó a que una parte de la Iglesia se acercara al pensamiento marxista, que en América Latina culminó con la teología de la liberación. ${ }^{23}$

Por último, en ambos países la intervención de EE.UU. fue importante, y se reforzó notablemente después de la revolución cubana. En 1961 se lanzó la alianza para el progreso, un programa de reformas pensado para responder a la amenaza revolucionaria. ${ }^{24}$ Sin embargo, los gobiernos reformistas y la trayectoria democrática fueron interrumpidos por golpes de Estado: en Brasil tempranamente (1964), lo cual favoreció la llegada a Chile de innúmeros intelectuales izquierdistas brasileños, hasta el bombardeo de la Moneda en 1973.

\section{La segunda mitad de los años cuarenta: el inicio de la guerra fría y la persecución de los comunistas}

El fin de la segunda guerra mundial consolidó un nuevo contexto político con fuertes rebatimientos en América Latina. ${ }^{25}$ En estos años, se puede observar, tanto en el caso brasileño como en el chileno, una fuerte presencia comunista en los barrios obreros y populares. Esto generó varias aprensiones, que fueron amplificadas por la preocupación para los buenos resultados electorales conseguidos por el Partido Comunista. Gran parte de la reflexión y de las iniciativas públicas centradas en el tema de los barrios populares, evocaron el riesgo para la democracia que representaba la presencia comunista en estas áreas. Como veremos, la Iglesia Católica Romana fue uno de los principales actores que intentó contener la expansión comunista en los barrios populares, orientando además gran parte del trabajo social que se desarrolló en ellos.

21 Manuel Caballero, Latin America and the Comintern, 1919-1943, Cambridge University Press, 2002. Elvira Concheiro, Massimo Modonesi, Horacio Crespo (eds), El comunismo: otras miradas desde América Latina, Universidad Nacional Autónoma de México, 2007.

22 Michael Fleet, The rise and fall of chilean christian democracy, Princeton (NJ), is ípipipinceton University Press, 1985. Michael Fleet, Brian Smith, The catholic church and democracy in Chile and Peru, Notre Dame (IN), Notre Dame Press 1999. Cristían Gazmuri, Eduardo Frei Montalva y su época, Santiago, Aguilar, 2000

${ }_{23}$ CEHILA, Historia general de la iglesia en América Latina. Salamanca, Ediciones Sígueme, 1994. Ondina González, Justo González, Christianity in Latin America. A History. Cambridge University Press, 2007. Silvia Scatena, In populo pauperum. La chiesa latinoamericana dal Concilio a Medellín, Il Mulino, 2007

24 Jeffrey Taffet, Foreign aid as foreign policy: the Alliance for Progress in Latin America. Routledge, 2012. Sobre la cuestión de la vivienda popular, véase: Benmergui, "The Alliance for... op. cit.

25 Gilbert Joseph, Daniela Spenser, In from the Cold. Latin America's new encounter with the Cold War. Durham, Duke University Press, 2008. 


\section{Las “favelas" de Río}

Después del final de la segunda guerra mundial y con el proceso de democratización posterior al Estado Nuevo, el Partido Comunista Brasileño (PCB) salió de la ilegalidad por un breve período (19451947) y obtuvo una fuerte visibilidad en la vida política brasileña. El número de militantes comunistas pasó de 100 en 1942 a cerca de 200.000 en $1945 .{ }^{26}$ A través de la redemocratización y la propuesta de una Unión Nacional y una alianza con los que resistieron al nazi-fascismo, el PCB decidió insertarse en los canales institucionales. Alcanzó casi el 10\% de los votos en las elecciones presidenciales de 1945 y logró una gran penetración en los centros urbanos, en particular en Río de Janeiro ( $27,5 \%$ de los votos). También consiguió elegir 15 de los 286 miembros de la Asamblea Constituyente y un senador, el entonces Secretario General del Partido, Luís Carlos Prestes.

Después de la promulgación de la nueva Constitución, que ocurrió en septiembre de 1946, los comunistas se lanzaron a la campaña electoral para los gobiernos y asambleas de los estados, elecciones que tuvieron lugar en enero de 1947. Obtuvieron excelentes resultados en las elecciones locales, eligiendo un gran número $(36 \%)$ de los representantes del Concejo Municipal del Distrito Federal. El período de actividad de los concejales comunistas en la Cámara fue corto, ya que el Partido fue devuelto a la ilegalidad por el gobierno del Presidente Eurico Gaspar Dutra, en mayo de 1947.

A pesar de ser corta, la actuación de los concejales comunistas fue intensa, especialmente en las favelas. El crecimiento del número de favelados ${ }^{27}$ y su estigmatización, la ausencia de servicios públicos y la represión policial en estos espacios constituyeron un conjunto de elementos que contribuyeron a la expansión de los ideales comunistas en estos lugares. Según lo descrito por Negro y Silva, "los comunistas revelaron gran agilidad en la organización de docenas de Comités Populares y Democráticos (CPDs), que estuvieron implicados en problemas del vecindario y discutieron temas tales como vivienda, costos de géneros de primera necesidad, educación, salud pública, esparcimiento, etc." 28 Aunque muchos de estos organismos no estaban ligados abiertamente al Partido Comunista, fueron influenciados en gran parte por militantes del Partido, sirviendo de estructuras legales para la inserción política de los comunistas en los barrios. ${ }^{29}$

La propuesta ideológica del PCB, que apuntaba a fortalecer la educación de las masas, se materializó a través de diversos mecanismos de organización del proletariado. Además de los CPDs, ejemplos se encuentran en las Uniones Femeninas o en los Comités por la paz en la campaña liderada por el PCB contra el envío de soldados brasileños a la guerra de Corea. ${ }^{30}$ Tales instituciones tenían una fuerte inserción en la vida cotidiana de los vecindarios. No se declaraban abiertamente comunistas, pero estaban bajo la influencia del PCB. Entonces, aunque no hayan sido cerradas por el Estado, estaban bajo

\footnotetext{
${ }^{26}$ Jose Antônio Segatto. Breve história do PCB. Belo Horizonte: Nossa Terra, 1989, p.56.

27 Moradores de favelas.

28 Antonio Luigi Negro y Fernando Teixeira da Silva, “Trabalhadores, sindicatos e política (1945-1964)" en Lucilia de Almeida Neves Delgado y Jorge Ferreira (org.). Brasil Republicano - o tempo da experiência democrática: da democratização de 1945 ao golpe civil-militar de 1964. Río de Janeiro: Civilização Brasileira, 2003, p.55.

En un reportaje del periódico Tribuna Popular, del 19 diciembre de 1945, el abogado Henrique Aranha Miranda, Secretario General del Comité Popular Democrático de Tijuca, explica la importancia de los comités democráticos: "desde la observación honesta y atenta de las iniciativas de los comités se puede concluir: fruto legítimo del espíritu cívico y democrático de los que los constituyen y que son liberales, conservadores o comunistas, católicos, protestantes o espíritas, capitalistas u obreros, estos comités luchan coherente y patrióticamente por la Unión Nacional, la destrucción de los remanentes del nazi-integralismo y la solución de los principales problemas nacionales, así como las reivindicaciones locales urgentes e inmediatas ".

29 Rafael Soares Gonçalves, Manuella Thereza Cabral Pessanha, Géssica Martins Mororó, "Pelo direito de permanecer: mobilização política e o acesso a serviços de água e luz nas favelas cariocas no período pós-Estado Novo", Libertas, v15, n², 2015.

${ }^{30}$ La guerra de Corea tuvo lugar entre 1950 y 1953 y aunque muchos países occidentales componían las fuerzas en defensa de la Corea del Sur, la mayoría de los soldados eran estadounidenses. A pesar de las presiones, Brasil no envió soldados. Este tema fue evocado en gran parte por el PCB, que buscó oponerse a la guerra y en favor de la paz, creando incluso comités para organizar a los trabajadores en la campaña contra la guerra. Sobre este tema, véase Ribeiro (2011).
} 
estricta vigilancia policial, como es posible constatar en los documentos del fondo de Policía Política del Archivo Público del Estado de Río de Janeiro (APERJ).

Los CDPs lucharon contra los desalojos de las favelas, y por mejoras en estos lugares, como la implementación de escuelas, grifos de agua, puntos de luz y vigilancia. Para eso, se elaboraban charlas y debates entre los candidatos y la población local. La acción comunista no describía las favelas como espacios provisorios o precarios, sino que ya las concebía como espacios en transformación, que podrían, mediante la movilización política y la intervención de las autoridades públicas, adquirir mejores condiciones de habitabilidad. El debate no se basó en la elaboración de políticas de vivienda para el desalojo de las favelas, sino que se convirtió en el mejoramiento gradual de estos espacios. La reflexión comunista insertaba las favelas en la dinámica urbana y comprendía que más allá de una vivienda, los habitantes de las favelas buscaban un lugar en la ciudad. ${ }^{31}$

Los habitantes de las favelas fueron parcialmente responsables del éxito del Partido Comunista en las elecciones de 1945 y 1947. De manera similar, muchas favelas no habrían sobrevivido a los innumerables procesos de desalojo de los años 1940 y 1950 sin la organización y asistencia de los comunistas. Eran uno de los pocos grupos políticos, que abogaban abiertamente por el derecho a la tierra de las favelas y cuestionaban directamente la legislación urbana de la época, reivindicando mejorías para los cerros cariocas. ${ }^{32}$ Aunque el PCB fue devuelto a la ilegalidad, el Partido mantuvo su presencia en las favelas de la ciudad. Muchos de los Comités Populares Democráticos se fueron transformando gradualmente en asociaciones locales de vecinos, con el objetivo de eludir la represión policial. ${ }^{33}$ Era común que los militantes comunistas subiesen a las favelas, donde realizaban un trabajo político de campo. ${ }^{34}$

Durante este período, las intervenciones directas de las autoridades públicas en las favelas fueron limitadas. El 6 de septiembre de 1946, el Gobierno Federal estableció una Comisión Interministerial para estudiar las causas de la expansión de las favelas, cuyas conclusiones solamente propusieron el fortalecimiento de los dispositivos represivos contra las favelas del código de obras de 1937. En 1946, el gobierno del Presidente Gaspar Dutra creó la Fundación de la Casa Popular, con el objetivo de aumentar la oferta de vivienda. Concomitantemente, varias comisiones fueron instituidas por la administración pública para analizar el problema de la vivienda y formular políticas públicas. El alcalde Mendes de Morais instituyó una Comisión municipal el 28 de noviembre de 1947 para lanzar la erradicación definitiva de las favelas. Aunque nada concreto fue producido, la Comisión tuvo, sin embargo, el mérito de organizar el primer censo de las favelas en $1948 . .^{35}$

El miedo de la influencia comunista, en el contexto de la guerra fría, comenzó a conducir gran parte del debate público sobre las favelas en la ciudad. El periodista Carlos Lacerda desempeñó un papel importante en la política local y nacional después de la segunda guerra. Comunista en su juventud, se convirtió en la principal figura anticomunistas en la política nacional. Apoyó, inclusive, el golpe de 1964. En 1948, publicó una colección de artículos sobre las favelas cariocas, llamados la batalla de Río de Janeiro. Estos artículos buscaron situarse entre el discurso oficial del gobierno y aquel del partido comunista. En 1960, fue elegido gobernador de la ciudad e invitó el sociólogo José Arthur Rios para la coordinación de servicios sociales. ${ }^{36}$ José Arthur Rios fue substituido por Sandra Cavalcanti, en 1962,

31 Rafael Soares Gonçalves, Manuella Thereza Cabral Pessanba, Géssica Martins Mororó, "Pelo direito de permanecer... op. cit.

32 Sobre la actuación del Partido Comunista en las favelas, véase Brodwyn Fischer, "The Red Menace Reconsidered: A Forgotten History of Communist Mobilization in Río de Janeiro's Favelas, 1945-1964, Hispanic American Historical Review, vo94, nº 1, 2014, p.1-33, Mauro Amoroso e Rafael Soares Gonçalves, "O advogado e os “Trabalhadores Favelados": Antoine de Magarinos Torres e a prática política nas favelas cariocas dos anos 1950 e 1960, Revista Estudos Históricos, v²9, no59, 2016, p.707-724.

33 Marco Cesar de Oliveira Pinheiro, O PCB e os Comitês Populares democráticos na cidade do Rio de Janeiro (1945-1947), tésis de maestria en história, Rio de Janeiro: UFRJ, 2007, p.55.

34 Rafael Soares Gonçalves, Manuella Thereza Cabral Pessanha, Géssica Martins Mororó, "Pelo direito de permanecer... Op. Cit.

35 Rafael Soares Gonçalves, Favelas do Rio de Janeiro. História e Direito, Rio de Janeiro: Ediciones Pallas y PUC, 2013.

${ }^{36}$ José Arthur Rios fue el principal coordinador del informe SAGMACS (Sociedade Mecanográficas Aplicadas aos Complexos Sociais, en portugués). SAGMACS fue creado en São Paulo en 1947, por el fraile dominicano francés Louis Joseph Lebret. 
cuando el gobierno de Carlos Lacerda abandonó definitivamente las políticas de rehabilitación de las favelas para empezar la eliminación de estos lugares, a través de la construcción de viviendas sociales en zonas periféricas.

Según Carlos Lacerda, "Si el gobierno quiere eliminar las fuentes del comunismo, debe dejar que se mejoren las condiciones de vida de los favelados." ${ }^{37}$ La gran influencia del PCB indujo al Estado y a la Iglesia Católica a adoptar medidas destinadas a neutralizar su influencia. El periódico católico $A$ Cruz anunció el riesgo de las acciones del comunismo y enfatizó su presencia en las favelas: "en estos pocos meses, [los comunistas] agitaron toda la vida nacional. De las favelas hasta al Parlamento no hay más tranquilidad. Si no lo hacen más cosas, es porque la policía y el ejército, que están a cargo de nuestra defensa y seguridad, han mantenido sus ojos abiertos y vigilantes." 38

La Iglesia, especialmente orientada por las encíclicas sociales, fomentaba un trabajo apostólico orientado a difundir la práctica de la religión y a ayudar a los pobres. Así, ocupaba los barrios populares donde estaban los comunistas. En 1937, con la Fundación del Instituto de educación social y familiar realizada por el Cardenal Arzobispo Sebastião Leme y bajo la fuerte influencia de los intelectuales católicos de la época, como Estela Faro y Alceu Amoroso Lima, profesionales cualificados (trabajadoras sociales y educadores familiares) empezaron a actuar en los diferentes órganos de asistencia del municipio, principalmente en aquellos centrados en la asistencia de los residentes de favelas. El propósito del Instituto era "formar entre las mujeres, no de una clase, sino de todas las clases sociales, una conciencia de la comunidad cristiana que substituiría el individualismo liberal y egoísta sin caer en la socialización inhumana y estatal. Para ello, capacitar las trabajadoras sociales, educadoras familiares y amas de casa para que sean, en el entorno en el que viven y trabajan, en los institutos en los que enseñan, o en los entornos sociales donde operan, elementos de conexión de anomalías sociales, verdaderos elementos de renovación personal y católica". ${ }^{39}$ (Lima, 1987:55). Este Instituto fue añadido a la Pontificia Universidad Católica de Río de Janeiro (PUC-Río) en 1946, imprimiendo la marca de la obra del apostolado laico al inicio de la asistencia social en Río de Janeiro. 40

El eslogan evocado por la iglesia en la posguerra en relación a las favelas era: "necesitamos escalar los cerros antes de que los comunistas de allí desciendan."41 Bajo la influencia del arzobispo de Río de Janeiro, Mons. Jaime Cámara, fue instituido, por decreto federal n ${ }^{\circ} 22.498$, del 22 de enero de 1947, la Fundación León XIII, que tenía la misión de "proporcionar una amplia asistencia social a los habitantes de los cerros, favelas y locales similares en Río de Janeiro." 42 Administrado por una junta compuesta por un representante de la Arquidiócesis, uno de la municipalidad y uno del refugio del Cristo Redentor ${ }^{43}$, las acciones de la Fundación se basaban en gran parte en la creación y animación de centros de asistencia social, que empezaron a construirse en las favelas de la ciudad.

Como representante del humanismo cristiano, Lebret ejerció una fuerte influencia en los estudios urbanos en el país. El informe fue publicado en el periódico o Estado de São Paulo, en abril de 1960. Para obtener más información sobre el informe y el trabajo de José Arthur Ríos y Louis Joseph Lebret, ver: Marco Antonio da Silva Mello et al., Favelas en Río de Janeiro. Ontem e hoje, Río de Janeiro, Editora Garamond, 2012.

37 Carlos Lacerda, Correio da Manhã, 26 de mayo de 1948.

38 A Cruz, 12 de mayo de 1946.

39 Arlete Alves Lima, Serviço Social no Brasil. A ideologia de uma década. São Paulo: Editora Cortez, 1987.

40 Rafael Soares Gonçalves, Soraya Silveira Simões y Leticia de Luna Freire, “A contribuição da Igreja Católica na transformação da habitação popular em problema público na França e no Brasil”, Cuadernos de Antropología Social, n³1, 2010.

41 Sociedade de Análises Gráficas e Mecanográficas Aplicadas aos Complexos sociais (SAGMACS). "Aspectos humanos da favela carioca". Em O Estado de S. Paulo, 8 e 15 de abril de 1960, São Paulo, p.28.

42 Artículo $1^{\circ}$ del decreto federal $\mathrm{n}^{\circ} 22.498$, del 22 de enero de 1947, véase en http://www2.camara.leg.br/legin/fed/decret/1940-1949/decreto-22498-22-janeiro-1947-341184-publicacaooriginal-1-pe.html (acceso en noviembre de 2018).

${ }^{43}$ El refugio de Cristo Redentor fue creado en 1936 por Raphael Levy Miranda, llamado el "apóstol de la asistencia social en Brasil" y un amigo del presidente Getúlio Vargas. Después de ser administrado por instituciones religiosas, el refugio pasó, en 1991, para la administración pública. (Rafael Soares Gonçalves, Soraya Silveira Simões y Leticia de Luna Freire, "A contribuição da Igreja Católica... op. cit. 
Basándose en los principios de la doctrina social de la Iglesia Católica y bajo la inspiración de las encíclicas sociales (Rerum Novarum y Cuadragésimo anno), la Fundación León XIII significó un esfuerzo de la Iglesia Católica para insertarse en los barrios obreros y defender los principios cristianos frente a la expansión comunista. Los trabajadores sociales ejercieron un fuerte control en la vida cotidiana de los residentes. Analizando los registros del Trabajo Social de la Fundación León XIII en la favela Praia do Pinto, es posible comprobar que cualquier trabajo de mejora de las casas tenía que pasar por el tamiz de los trabajadores sociales. Además, controlaban la asistencia de los niños a la escuela, la limpieza de las casas, promovían actividades religiosas e investigaban si las informaciones fornecidas por las familias eran verdaderas.

Apoyada en los principios de educación, salud y vivienda, la Fundación León XIII también promovió trabajos de saneamiento, siendo, incluso, criticada virulentamente por promover la perpetuación de las favelas. ${ }^{44}$ Actuó en varias favelas, implantando en algunas de ellas servicios básicos tales como agua, alcantarillado, luz y mejorías en los accesos. Como explica Samuel Oliveira, ${ }^{45}$ esta institución fue una de las principales armas de la política pública practicada por el municipio en las favelas, siendo incorporada a la administración directa y vinculada al organismo de Trabajo Social del Estado de Guanabara, en 1961. Las intervenciones públicas en favelas durante este período mantuvieron un difícil equilibrio. Según Rafael Soares Gonçalves, ${ }^{46}$ hubo una tolerancia precaria, que intervino puntualmente con algunas mejorías, pero mantuvo el carácter provisorio de las favelas. En el informe de 1949 de la Fundación León XIII, ya es posible ver, por ejemplo, la idea de una urbanización selectiva, puesto que "hay favelas que deben ser desalojadas y sus habitantes ubicados en viviendas populares en otras áreas. Hay favelas que deben convertirse gradualmente en barrios populares, mejorando casas a través de planes de urbanización." 47

Para permitir que las "poblaciones socialmente emergentes" se vuelvan "menos sujetas a la explotación de políticos inescrupulosos y de agitadores extremistas", la institución también ejerció una fuerte influencia en la vida asociativa local, promoviendo la formación de diversas asociaciones de residentes y comisiones de luz, responsables de la distribución de la electricidad en algunas favelas.

\section{Las "poblaciones" de Santiago}

Si bien durante las primeras décadas del siglo XX los "conventillos" estuvieron en el centro del debate sobre la vivienda popular, no eran pocas las personas humildes que vivían en los bordes de la ciudad, donde arrendaban un "piso" (un terreno), compraban un sitio a plazo, o simplemente ocupaban espacios baldíos.48 A través de estas prácticas, que a menudo tenían algún grado de informalidad, surgieron numerosas "poblaciones" ubicadas en los sectores periféricos. Según el diario comunista El Siglo, en 1947 en Santiago vivían en ellas "no menos de 400 mil personas", que carecían "de todos o algunos de los servicios urbanos: luz, agua, alcantarillado". ${ }^{49}$

Una tesis de 1945 nos informa sobre una de estas, la "población Areneros". La tesis fue redactada por Elena López, una visitadora social de la Escuela Elvira Matte de Cruchaga, que había sido creada en 1929 con una clara orientación confesional, dentro de la Universidad Católica. ${ }^{50}$ La población Areneros, ubicada en la ribera del río Mapocho, se describía como un "caserío", un conjunto de "ranchos de

${ }^{44}$ Rafael Soares Gonçalves, Soraya Silveira Simões y Leticia de Luna Freire, “A contribuição da Igreja Católica... op.cit.

45 Samuel Oliveira, "Trabalhadores favelados": identificação das favelas e movimentos sociais no Rio de Janeiro e em Belo Horiz̧onte, Tésis de doctorado en História, Rio de Janeiro: PPGHPBC-CPDOC/FGV, 2014, p. 67.

46 Rafael Soares Gonçalves, Favelas do Rio de Janeiro..., op. cit.

47 Fundação Leão XIII, citado por Samuel Oliveira, "Trabalbadores favelados": identificação das favelas... op. cit., p.68.

48 De Ramón, "La población informal... op. cit.

49 "Problemas de las poblaciones", El Siglo 19.11.1947, p.3. Según el censo de 1940, Santiago tenía poco más de un millón de habitantes.

50 María Angélica Illanes, 2006, Cuerpo y sangre de la política. La construcción histórica de las Visitadoras Sociales (1887-1940), Santiago, LOM 
miseria", donde las viviendas estaban "construidas con unas cuantas tablas, latas, ramas y adobes viejos". Se había formado en 1940, cuando la Municipalidad de Las Condes facilitó un terreno para reubicar unas 50 familias, que se dedicaban a extraer arena del río. En 1945, las familias habían alcanzado el número de 260 y estaban organizadas con el fin de mejorar las condiciones de la población. A través de peticiones a la Municipalidad y juntando dinero entre los habitantes, el "Comité de Pobladores" había conseguido instalar pilones de agua potable y postes de luz, y quería realizar una obra de defensa contra las crecidas del río. ${ }^{51}$

Según López, era “digna de encomio la obra desarrollada por el comité, pero desgraciadamente no sólo tiene el fin de ayuda, sino que también tiene un fin político, pues como hemos dicho anteriormente la mayoría de los habitantes son comunistas y tratan de atraer y comunicar sus ideas a los demás". ${ }^{52}$ La visitadora se mostraba preocupada por esta influencia, que había alcanzado una clara hegemonía. Sin embargo, destacaba una serie de iniciativas que se habían puesto en marcha, inspiradas por el catolicismo: la creación de un sindicado alternativo al "Sindicado Rojo", impulsado por Monseñor Cabrera, el cual funcionó hasta el fallecimiento del Párroco; la instalación de una escuela para los niños de la población, en la cual participaban estudiantes de la Universidad Católica; la construcción de una "capillita" por parte de la Acción Católica, en la cual se celebraba la misa todos los domingos. López concluía declarando que "la hermosa labor desarrollada por los católicos de la comuna de Providencia y de Las Condes, contrarrestará en parte los grandes daños que causa el Comunismo". ${ }^{53}$

La tesis de López muestra que los habitantes de las poblaciones periféricas, incluso las más pobres y humildes, estaban organizados y tenían capacidad de interactuar con las instituciones. Muestra, además, que existía una densa red de actores externos, cuya acción de ayuda muchas veces estaba inspirada por los valores católicos, o por la ideología comunista. La disputa cultural y política entre catolicismo y comunismo no era nueva, como no era nueva sus presencias en los barrios populares. ${ }^{54} \mathrm{Sin}$ embargo, en un contexto marcado a nivel internacional por el fin de la segunda guerra mundial y el inicio de la guerra fría, ${ }^{55}$ estas intervenciones comenzaron a asumir características nuevas.

En 1946 los comunistas apoyaron el candidato presidencial Gabriel González Videla, pasando a integrar su Gobierno, junto a los Radicales y los Liberales. En las elecciones municipales de abril de 1947, el Partido Comunista obtuvo un resultado notable, convirtiéndose en la tercera fuerza política, lo cual generó tensiones en la coalición de Gobierno. Además, estos conflictos fueron alimentados por la estrategia política de los comunistas, que plantearon la necesidad de "impulsar la lucha de masas para lograr nuevos avances en la realización del programa". ${ }^{56}$ Efectivamente, los paros y las movilizaciones populares se intensificaron notablemente durante 1947, creando algunos duros conflictos. ${ }^{57}$ En los

51 Elena López, "Población Arenera", memoria para optar al título de visitadora social, Escuela de servicio social Elvira Matte de Cruchaga, Santiago, 1945

52 Ibid. p.11

53 Ibid. p.14

54 Macarena Ponce de León, Gobernar la pobreza. Prácticas de caridad y beneficencia en la ciudad de Santiago, 1830-1890, DIBAM, Centro de Investigaciones Diego Barros Arana, 2011. Sergio Grez, De la "regeneración del pueblo" a la huelga general. Génesis y evolución histórica del movimiento popular en Chile (1810-1910), Santiago, DIBAM, Centro de Investigaciones Diego Barros Arana, 1997; Rodrigo Hidalgo, Tomás Errázuriz, Rodrigo Booth. "Las viviendas de la beneficencia católica en Santiago: instituciones constructoras y efectos urbanos (1890-1920)." Historia 38.2, 2005, pp. 327-366

55 Olga Ulianova, “Algunas reflexiones sobre la Guerra Fría desde el Fin del Mundo”, en Fernando Purcell y Alfredo Riquelme (eds.) Ampliando miradas. Chile y su bistoria en un tiempo global. Santiago, Ril, 2009, pp. 235-259

${ }^{56}$ Esto era el título de un artículo de El Siglo, del 30.11.1946, en donde se presentaba el texto completo del discurso pronunciado por el secretario del Partido Comunista, diputado Ricardo Fonseca. Además, véase María Soledad Gómez, "Factores nacionales e internacionales de la política interna del Partido Comunista de Chile (1922-1952)" en Augusto Varas (ed.) El Partido Comunista en Chile, Santiago, FLACSO-CESOC, 1988, pp. 65-139. Rolando Álvarez, 2011, Arriba los pobres del mundo. Cultura e identidad politica del Partido Comunista de Chile entre democracia y dictadura. 1965-1990, Santiago, LOM, 2011.

57 Jody Pavilack, Mining for the Nation. The politics of Chile's coal communities from the popular front to the cold war, the Pennsylvania State University Press, 2011. Cristián Pozo, Ocaso de la unidad obrera en Chile: confrontación comunista-socialista y la división de la CTCH (19461947), Tesis para optar al grado de Magíster en Historia, Universidad de Chile, 2013. Nicolás Acevedo, "Un fantasma recorre el 
mismos meses, en Santiago aumentaron exponencialmente los lanzamientos judiciales, que involucraron miles de arrendatarios. El intendente Frías, de militancia comunista, intentó limitar el fenómeno, pero entre julio y agosto se aprobó su desafuero. ${ }^{58}$ En septiembre, todos los comunistas fueron alejados de sus cargos institucionales, $y$, el año sucesivo, fueron proscritos de la vida nacional a través de la "ley maldita". 59

Los lanzamientos interesaron centenares de familias que arrendaban piezas en el centro, pero también fueron involucrados las poblaciones periféricas. Entre estas últimas, durante los últimos meses de 1947, la prensa se interesó a dos casos. Se trataba de la población Gabriela Mistral (o Anexo Lautaro) y la población Zañartu. ${ }^{60}$ Respecto a la primera, El Siglo informaba que existía un orden de desalojo para 140 familias que arrendaban el terreno desde hace 10 años. ${ }^{61}$ Según este diario, el problema se generó cuando dos dirigentes socialistas compraron la propiedad y empezaron a planear el lanzamiento. ${ }^{62}$ En cambio, El Diario Ilustrado, de tendencia conservadora, y La Opinión, socialista, acusaron los comunistas de haber alentado el asalto de los terrenos en julio de 1946, despojando así las familias que estaban ahorrando para comprar esos mismos terrenos, con el apoyo de los dirigentes socialistas. ${ }^{63}$ Por otro lado, las familias de la población Zañartu se estaban movilizando para pedir la expropiación de los terrenos que ocupaban. ${ }^{64}$ Las fuentes no aclaran cuándo y cómo estas familias se habían instalado en el lugar, pero, según El Diario Ilustrado, los terrenos "fueron ocupados de la noche a la mañana por caravanas perfectamente organizadas". ${ }^{65}$ Las autoridades se movilizaron para encontrar una solución. Después de considerar varias opciones, se decidió trasladar la población Zañartu al terreno llamado Nueva La Legua, y la población Gabriela Mistral a Los Nogales. Las dos operaciones se iniciaron en enero de 1948. ${ }^{66}$

Varios periódicos, como El Diario Ilustrado y La Opinión, comenzaron a acusar los "agitadores comunistas" de alentar el pueblo a la usurpación de sitios eriazos. ${ }^{67}$ El Siglo, en cambio, rechazó la tesis de la agitación política, destacando como, frente a los especuladores y la falta de vivienda, al pueblo "no le quedó otro remedio que irse a habitar a los terrenos eriazos y abandonados, en lo que levantó sus ranchitos con cuanto material pudo hacerlo, por inadecuado que pareciera". ${ }^{68}$ Las fuentes revisadas no permiten aclarar si efectivamente el Partido Comunista incentivó y organizó las ocupaciones de terrenos. Lo que sí es cierto, es el repetido apoyo a las demandas de los pobladores, cuando estos se oponían a órdenes de lanzamiento, cuando pedían la expropiación de un terreno para solucionar situaciones

campo: Anticomunismo, sindicalización campesina y Ley de Defensa Permanente de la Democracia (Chile, 1946-1948)", Cuadernos de Historia, 42, 2015, pp. 127-151.

${ }^{58}$ Espinoza, Para una historia... op. cit.

${ }^{59}$ Carlos Hunees, La guerra fría chilena: Gabriel González Videla y la Ley Maldita, Santiago, Debate, 2009

${ }^{60}$ Sobre estos dos casos, además de las fuentes citadas en las siguientes notas, véase: Jorge Rojas, La lucha por la vivienda en tiempos de González Videla: Las experiencias de las poblaciones Los Nogales, Lo Zañartu y Luis Emilio Recabarren en Santiago de Chile, 1946-1947”, Revista Irquierda, 39, 2018.

61 "Hay orden de desalojo contra 140 pobladores" El Siglo, 27.08.1947, p.1

${ }^{6} 2$ El Siglo siguió defendiendo esta versión: "Con tinterilladas pretenden lanzar a los pobladores de "Gabriela Mistral”, El Siglo, 21.11.1947, p.8; "Siguen sin solución problemas de la población "Gabriela Mistral”, El Siglo, 06.12.1947, p.4

63 "Frente Nacional de la Vivienda impulsará reformas de las leyes de la Caja de Habitación Popular", El Diario Ilustrado, 10.11.1947. "El terror comunista les quitó sus tierras", La Opinión, 16.10.1947. "86 familias instaladas en la chacra de la Caja del Seguro Obligatorio", La Opinión, 13.01.1948, p.1. "Insisten en desmentir lo de la Población "Gabriela Mistral”, El Siglo, 23.11.1947, p.9.

${ }^{64}$ Desde final de septiembre de 1947, El Siglo dedicó numerosos artículos a la población Zañartu.

65 "El nuevo problema de las poblaciones "fantasmas" estudia director del depto de la vivienda, comandante Riesle", El Diario Ilustrado, 05.11.1947.

${ }^{66}$ Las operaciones fueron cubiertas por varias noticias de los principales periódicos nacionales.

67 "Se impedirá la formación de poblaciones callampas", El Diario Ilustrado, 14.01.1948, p. 2. "Agitadores comunistas estarían incitando a que sean ocupados los sitios eriazos de Santiago", El Diario Ilustrado, 18.02.1948, p. 5. "Las poblaciones callampas" son obra de agitadores comunistas", La Opinión, 15.01.1948. "Plan para crear dificultades de orden social al Gobierno realizan comunistas", La Opinión, 18.02.1948. En relación a estas noticias, hay que considerar que en estos meses las acusaciones a los comunistas se iban multiplicando, desembocando finalmente en la aprobación de la ley maldita.

68 Arcadio Meza, "Vida, pasión y muerte de las poblaciones callampas", El Siglo 30.01.1948. 
irregulares, o cuando se movilizaban para conseguir obras de adelanto. Efectivamente, revisando la prensa comunista de los últimos años cuarenta, ${ }^{69}$ es evidente la presencia del Partido en los barrios populares, en particular algunos, como el Zanjón de la Aguada y Nueva La Legua, donde, además de las juntas directivas, se crearon comités femeninos o comités de "agregados". ${ }^{70}$ Esto era coherente con la política planteada por el Partido, que buscó ampliar su influencia más allá de los sindicatos. En este sentido, las poblaciones se transformaron en un lugar importante de trabajo político, el cual se centró en la lucha contra "la carestía de la vida". A comienzo de 1946 Luis Reinoso escribía: "El Partido ha transformado la acción aislada de cada comité o junta en un movimiento unificado, lo que ha permitido sumarlo a las luchas contra la especulación, en defensa de los arrendatarios lanzados, por viviendas higiénicas, por la ayuda a los escolares indigentes y por la defensa del régimen democrático". ${ }^{71}$

La Iglesia también estaba presente en estos barrios. Al parecer, durante estos años, no se crearon evidentes conflictos con los comunistas. En la misma población Nueva La Legua, junto a los primeros pobladores, llegó el padre Maroto, quien fundó la parroquia San Cayetano y promovió numerosas iniciativas de mejoras de la población, entre las cuales la creación de una policlínica. ${ }^{72}$ En esta trabajaron visitadoras sociales de la Escuela Elvira Matte de Cruchaga, quienes organizaron un Centro de Madres y uno de niñas, y quienes, además, llevaron a cabo una encuesta a 200 familias de la población. ${ }^{73}$ En la población Los Nogales, José Garrido, párroco de Jesús Obrero, se movilizó desde los primeros días para ayudar las familias que estaban llegando. ${ }^{74}$ La parroquia, que estaba a cargo de la Compañía de Jesús, había sido fundada desde hace pocos años, a partir de la labor apostólica desarrollada en el sector por el padre Francisco Correa sj. Con el tiempo, gracias a la iniciativa de los sacerdotes jesuitas, en Los Nogales se desarrollaron varias obras de adelanto, entre la cuales la construcción de unas capillas y de la escuela Maria Goretti. ${ }^{75}$

\section{La segunda mitad de los años cincuenta: la creación del CELAM y la Revolución Cubana}

Durante los años cincuenta, la Iglesia Católica inició una reforma de su acción pastoral, poniendo mayor atención a los pobres y a las masas populares. Un hito importante fue la creación del CELAM en 1955. Una definitiva legitimación de estas tendencias llegó con el Concilio Vaticano II. Esto fue anunciado a pocos días de la victoria de la revolución cubana, que significó un cambio sustancial de la percepción del comunismo en América Latina.

En los años siguientes a la victoria de Castro, se profundizaron las tensiones de la guerra fría en la región, así como se hizo más dura la confrontación entre iglesia y comunismo, sobre todo en los barrios populares. La tensión se manifestó antes en Brasil y se intensificó en el caso chileno, en parte por la estructura política, donde los principales actores eran el Partido Demócrata Cristiano y una coalición de izquierda que incluya el Partido Comunista.

\footnotetext{
${ }^{69}$ En julio de 1948 fue prohibida la publicación de El Siglo. Para remplazarlo, y hasta octubre de 1952, circuló el periódico Democracia.

${ }^{70}$ Con "agregados" o "allegados" se indican las personas que viven en una vivienda, sin ser parte del núcleo familiar principal.

${ }^{71}$ Luis Reinoso "La solución a los problemas nacionales a través de las enseñanzas del XIII congreso", Revista Principios, n” 5657, febrero-marzo de 1946. Además, véase: Gómez, "Factores nacionales ... op. cit.

72 Paulo Álvarez, Legua emergencia: una historia de dignidad y lucha, Santiago, Ediciones Universidad Diego Portales, 2014.

73 María Muñoz, Problemas sociales de la Población "Nueva La Legua", Memoria para optar al Título de Visitadora Social de la Escuela "Elvira Matte de Cruchaga", Santiago, 1952

74 Durante enero de 1948, El Diario Ilustrado publicó varias noticias al respecto.

${ }^{75}$ Corporación Cultural USACH, Memoria social de la población Los Nogales (1947-2015), Santiago, 2016. Andrés Lira, Juan Manosalva, Luis Roblero, Gonzalo Vergara, Larry Yévenes, Historia de las parroquias jesuitas en la zona oeste de Santiago, Santiago, 1989
} 
Sin embargo, las reformas promovidas por el CELAM y el Concilio Vaticano II, provocaron varias convergencias entre el catolicismo y el marxismo. Esto es bastante evidente en la práctica pastoral en los barrios populares, que generó una crítica interna de las acciones de la propia Iglesia. Surgió una acción más progresista, especialmente con la consolidación, ya en los años 1970, de la teología de la liberación. El contacto pastoral con la realidad también trajo consigo una percepción de la realidad política del problema. ${ }^{76}$

\section{Las Favelas de Río}

Un nuevo capítulo del conflicto entre los comunistas y la iglesia se estableció con la creación de la Unión de los Trabajadores Favelados (UTF) en 1954, creada bajo la inspiración del abogado Antoine de Magarinos Torres, después de haber sido contactado por los residentes de la favela del Borel para defenderlos de un proceso de desalojo movido por la empresa Borel Meuren, que quería lotear las tierras donde se encontraba la favela. ${ }^{77}$ Aunque la UTF fue una entidad en la cual los miembros gozaban de cierta autonomía, a través de los informes de sus reuniones es posible observar la fuerte ascendencia de Magarinos Torres en el funcionamiento de la asociación. Si bien no hemos encontrado registros para verificar la afiliación de Magarinos al PCB, es notorio su proximidad al Partido Comunista. Magarinos Torres fue un importante miembro del movimiento de juristas por la paz y llegó a coordinar el Comité de apoyo a la paz de Río de Janeiro, entidades vinculadas al PCB, ${ }^{78}$ que movilizaron la sociedad contra el envío de soldados a la guerra de Corea.

Desde la favela del Borel, en el barrio de Tijuca, los centros de la UTF se extendieron a otras favelas y buscaron representar directamente los favelados delante las autoridades públicas, a veces desempeñando el papel de Asociación de vecinos. La UTF se declaró independiente de cualquier partido político, pero la ayuda comunista fue fundamental para sus actividades, como demuestra la intensa cobertura dada por el periódico comunista Imprensa Popular a sus iniciativas. Los métodos empleados por la UTF, y principalmente por su fundador, fueron criticados constantemente. El periódico A Cruz, del 9 de mayo de 1954, llama Magarinos Torres y los comunistas de falsos profetas:

“aprovechando la desesperación de los habitantes de las favelas, los comunistas cumplen las órdenes del Kominform. El rusófilo Magarinos Torres visita diariamente con su demagogia el Morro de Santa Martha (...). Sus discursos diarios son la mejor prueba de sus intenciones no confesadas. Insulta, en un lenguaje vulgar y violento, las autoridades constituidas y hace promesas irrealizables."

Según el informe de la Sociedad de análisis gráficos y mecanográficos aplicado a complejos sociales (SAGMACS) ${ }^{79}$, un famoso estudio sobre las favelas emprendido por la institución creada por el fraile dominicano Joseph Lebret, la UTF quemó las casas de todos los residentes que no pagaron la contribución obligatoria a la asociación y también obligaron a las mujeres y los niños a participar en las manifestaciones. Estas visiones muestran otra forma de ver el desempeño de la entidad y de Magarinos Torres, y es imprescindible para entender los conflictos entre los comunistas y la Iglesia sobre los barrios marginales y los proyectos de la ciudad en el período.

\footnotetext{
76 Carlos Alberto Steil, Relações entre igreja, estado e favela na atuação pastoral da Arquidiocese do Rio de Janeiro, Tésis de maestria en Teologia, Rio de Janeiro: PUC-Rio, 1984, p.104.

${ }_{77}$ Sobre el abogado Magarinos Torres y la UTF, véase: Mauro Amoroso e Rafael Soares Gonçalves, ”O advogado e os "Trabalhadores Favelados"... op. cit.; Samuel Oliveira, "Trabalhadores favelados"..., op. cit. y Brodwyn Fischer, "Democracy, Thuggery and the Grassroots: "Antoine Magarinos Torres and the União dos Trabalhadores Favelados in the Age of Carioca Populism”, Nuevo Mundo Mundos Nuevos - Colloques, 2013, acceso em noviembre de 2018.

78 Mauro Amoroso e Rafael Soares Gonçalves, ”O advogado e os “Trabalhadores Favelados”..., op. cit.

79 Sociedade de Análises Gráficas e Mecanográficas Aplicadas aos Complexos sociais (SAGMACS). "Aspectos humanos da favela carioca... Op.Cit., p.31.
} 
La visibilidad política lograda por la UTF estimuló la aparición de nuevas iniciativas para barrer la "amenaza roja". En 1955, durante la realización del Congreso Eucarístico Internacional en Río de Janeiro, el ya popular obispo auxiliar de la ciudad, monseñor Helder Câmara, fue alentado por el entonces obispo primado de Francia, Cardenal Gerlier, a dedicar su capacidad de trabajo a las favelas, lo que determinó la creación de la Cruzada San Sebastián el 29 de octubre de $1955 .{ }^{80}$ La Cruzada fue una entidad privada, cuyo objetivo era ofrecer soluciones humanas y cristianas para resolver el problema de las favelas. Las acciones adoptadas por la Cruzada, sintetizadas en urbanización, humanización y cristianización, tuvieron como objeto urbanizar la totalidad de las favelas de Río de Janeiro para el cuarto centenario de la ciudad, el 20 de enero de 1967.

Aunque el artículo 4 de los estatutos de la Cruzada San Sebastián afirma que la misma actuaría en estrecha colaboración con la Fundación León XIII, la primera asumió cierto protagonismo en la intervención católica en las favelas de la ciudad. La Cruzada reflejó los cambios que estaban ocurriendo en la Iglesia latinoamericana. En el contexto de ya mencionado Congreso Eucarístico Internacional, se fundó el Consejo Episcopal Latinoamericano (CELAM) y se celebró su primera Conferencia. En esa instancia, el párrafo 79 de la declaración que emitieron los obispos latinoamericanos la importancia de pensar la cuestión de la vivienda obrera. "La Conferencia siente el deber de subrayar de la manera más decidida, la urgente necesidad de que todos los católicos colaboren con empeño para buscar, a la luz de la doctrina de la Iglesia, una justa solución; y con tal fin acuerda hacer sobre este punto un llamamiento especial." ${ }^{11} \mathrm{Al}$ mismo tiempo, se mantenía una retórica anticomunista fuerte. El párrafo 83 recitaba:

Mientras pone el acento sobre la necesidad de desarrollar una siempre más amplia e intensa actividad social y benéfica en favor de las clases más necesitadas, la Conferencia no quiere cejar en el deber que le incumbe de llamar enérgicamente la atención de todos los católicos, sobre las insidias y peligros de las doctrinas marxistas y de la propaganda del comunismo, y sobre la necesidad de precaverse y defenderse contra ellas, principalmente allí donde estén más desarrolladas. ${ }^{82}$

Utilizando recursos obtenidos con el auxilio de subvenciones públicas otorgadas por el Presidente Café Filho, de donaciones privadas y la concesión de derechos por el gobierno federal para aterrar, lotear y vender terrenos ubicados entre la Avenida Brasil y la bahía de Guanabara (Decreto federal $\mathrm{N}^{\mathrm{o}}$ 39.635, de 19 de julio de 1956), la Cruzada logró intervenir en varias favelas, además de construir un conjunto de edificios en el adinerado barrio de Leblon, junto a la Laguna Rodrigo de Freitas, para albergar una parte de los vecinos de la favela vecina, llamada Praia do Pinto. ${ }^{83}$ Se trata de un conjunto de edificios de 9 pisos que tienen 910 departamentos, que fueron inaugurados el día de San Sebastián, el santo patrono de la ciudad, el 20 de enero de 1957. Estos edificios, llamados barrio San Sebastián, fueron sin duda la obra más visible de la cruzada.

Los asignatarios del barrio San Sebastián podrían acceder a la posesión definitiva del departamento, después de un período de 15 años de pago de prestaciones, cuyo valor variaba del 8 al 15\% del salario mínimo, siempre que cumplan determinadas condiciones, como la prohibición de alquilar, transferir o modificar los edificios sin el consentimiento expreso de la Cruzada de San Sebastián. La Cruzada ejerció un control riguroso sobre los residentes. En primer lugar, los solicitantes de la favela

\footnotetext{
${ }^{80}$ Rafael Soares Gonçalves, Soraya Silveira Simões y Leticia de Luna Freire, “A contribuição da Igreja Católica... Op.Cit.

81 Declaración de los cardenales, obispos y demás prelados representantes de la jerarquía de América Latina reunidos en la Conferencia Episcopal de Rio de Janeiro, $1^{\text {a }}$ Conferencia General del CELAM, 1955 in http://www.iglesiacatolica.org.uy/departamento-de-catequesis/files/2012/08/rio.pdf (junio de 2018).

82 Ibid.

83 Además de la instalación de redes de electricidad en varias favelas, la Cruzada urbanizó parcialmente la favela del Morro Azul, construyendo allí un edificio con 48 apartamentos-y totalmente la favela del Parque Alegria. Intermedió la instalación de redes eléctricas en 51 favelas, construyó redes de agua en diez favelas y negoció la instalación de una docena de teléfonos públicos en favelas de la ciudad. Véase: Brodwyn Fischer, A poverty of rights: citizenship and inequality in twentiethcentury

Rio de Janeiro. Stanford: Stanford University Press, 2008.
} 
Praia do Pinto debían cumplir los criterios establecidos por la Asociación Católica: haber vivido por lo menos cuatro años en la favela, siendo relativamente pobres, teniendo una familia legalmente constituida, o al menos "respetando la moral natural", teniendo hijos y sin delincuentes en la familia. ${ }^{84}$

Se difundió un Decálogo del caballero de San Sebastián, una especie de hermandad masculina creada por Mons. Cámara, el cual evidencia que la cruzada proyectaba oponerse directamente al plan de expansión comunista en las favelas. En el séptimo punto, el decálogo recitaba: "el comunismo no resuelve nada", o por medio de ciertas disposiciones del reglamento de procedimiento de la nueva vecindad, que prohibió, por ejemplo, cualquier reunión de naturaleza política en los departamentos. ${ }^{85}$

En el contexto del Congreso de los favelados, organizado por la Cruzada São Sebastián en enero de 1957, Mons. Helder Câmara dijo: "no estamos en una sesión política o religiosa. No somos iguales a los candidatos que aparecen antes de las elecciones y luego desaparecen sin cumplir lo que dicen. Somos hombres que quieren unirse en torno a un ideal, hombres católicos, protestantes, espíritas o lo que sea, decididos a mejorar la vida de miles. Sólo temo a los que no creen en Dios, los comunistas. Tenga cuidado, porque para ellos cuanta más miseria haya más campo habrá para explorar." ${ }^{86}$ Varios documentos de la Cruzada destacaron el peligro de la influencia comunista, como demuestra el extracto debajo de las actas de la $9^{\circ}$ reunión del Consejo Deliberativo de la Cruzada San Sebastián del 10 de febrero de 1959. "Frente a dos grandes peligros: la reforma agraria promovida por los comunistas o por iniciativa del gobierno con fines demagogos, la Iglesia tiene la obligación de enfrentar el problema y utilizar las tierras de las diócesis terratenientes" 87 , para crear colonias rurales para los habitantes de las favelas.

Después de la inauguración de los edificios, la presencia de los trabajadores sociales continuó, incluso de manera más intensa, en las vidas de los ex-favelados. A las 22h00, había el toque de queda. Los conflictos entre vecinos e incluso entre marido y mujer siempre fueron llevados al servicio social, que, en los primeros años, trabajaban en uno de los edificios del conjunto. Tres años después de la inauguración, el estudio de SAGMACS (Sociedad para Análisis Gráfica y Mecanográfica Aplicada a los Complejos Sociales) ${ }^{88}$ realizó una evaluación crítica de la iniciativa de la Cruzada San Sebastián. En esta, la crítica caería sobre los procedimientos de acompañamiento social de los residentes, pensados en un trabajo conjunto entre los ayudantes de la Cruzada y los trabajadores sociales de la Fundación León XIII, que actuaban en la favela Praia do Pinto. El control de la conducta de los residentes en los departamentos siguió siendo ejercido por los trabajadores sociales de la Cruzada, los cuales, según los autores del estudio, manifestaban un "paternalismo ingenuo" de la política de vivienda de la Cruzada destinada a las favelas. En el texto, el discurso de un residente insatisfecho con la presencia de los trabajadores sociales hizo hincapié en este sesgo: "quieren mantener un régimen de internado para niñas en los bloques de departamentos." 89

Además de las numerosas intervenciones en varias favelas y la construcción de estos edificios en el barrio de Leblon, la Cruzada San Sebastián también buscó imponer su voluntad a las asociaciones de residentes de favelas. La cruzada lanzó un debate sobre el desarrollo de comunidades en las favelas y jugó un papel importante en la estructuración política de las asociaciones de residentes locales. El 6 de enero de 1957, algunos días después de que las primeras familias se trasladaran al barrio de San Sebastián en Leblon, Mons. Cámara participó en el ya citado Congreso General de los representantes de favelas. Los objetivos del Congreso eran eminentemente políticos, y buscaban, sobre todo, según el arzobispo, alejar

\footnotetext{
${ }^{84}$ Enny Guarnieri, Uma experiência de promoção social. Cruz̧ada São Sebastião. Rio de Janeiro: CBCISS. 1965, p.2-3.

${ }^{85} \mathrm{Nadyr}$ Coutinho, Um ensaio de aplicação das técnicas de organização social de comunidade num projeto piloto de conjunto residencial para exfavelados. Rio de Janeiro: Sesc, 1959, p.94-95.

86 Don Helder Câmara, Tribuna da Imprensa, 7 de janeiro de 1957.

87 Núcleo de Memória da PUC-Rio. Acervo Maria Luiza e Edgar Amarante, Caja 1.

${ }^{88}$ El SAGMCS fue fundado por el fraile dominicano francés Joseph Lebret. Este estudio fue coordinado por José Arthur Ríos y es un trabajo académico pionero sobre las favelas de la ciudad.

89 Sociedade de Análises Gráficas e Mecanográficas Aplicadas aos Complexos sociais (SAGMACS). "Aspectos humanos da favela carioca... op. cit.
} 
de las favelas el peligro comunista: "el Congreso de los representantes de las favelas significa un punto de lanza democrática en feudos que los comunistas imaginaban que les pertenecía"90

Aunque la Cruzada San Sebastián se transformó en un organismo casi oficial de implementación de la política gubernamental en las favelas, empezó a perder influencia tras la elección de Carlos Lacerda como gobernador local, en 1960. Los cambios institucionales introducidos por el nuevo gobierno, junto con el conflicto político entre éste y el obispo auxiliar de Río de Janeiro, Mons. Cámara, terminaron provocando la transferencia de este último a la diócesis de Olinda/Recife, reduciendo enormemente el dinamismo de la Cruzada.

En relación a la iglesia, las contradicciones se vieron reforzadas. La Conferencia Episcopal Brasileña apoyó las reformas propuestas por el gobierno del presidente João Goulart, pero algunos obispos se manifestaron en contra y participaron de la organización de las marchas con Dios por la familia y por la libertad, que se extendieron en varias ciudades del país. La Iglesia Católica tuvo una actuación ambigua poco después del golpe. Varios cristianos fueron arrestados, pidieron asilo en embajadas o se fueron para el exilio, mientras que otros fueron parte del primer gobierno militar o incluso de los órganos represivos. ${ }^{91}$

Sin embargo, en el transcurso de los años de la dictadura, la Iglesia Católica en Brasil, especialmente con la expansión de la teología de la liberación, asumió una posición crítica y de oposición al régimen. Esto también se vio manifestado en el contexto latinoamericano. La Conferencia Episcopal Latinoamericana de Medellín, en 1968, trajo denuncias de las estructuras de desigualdad social y una reflexión más amplia, política e integral de la noción de liberación del pueblo. La Conferencia de Puebla en México fue más allá y confirmó la "opción preferencial por los pobres". Según Luiz Alberto Gomés de Souza, desde 1968 hasta 1979, fue un período eclesial extremamente brillante en América Latina, justamente en el período más duro de golpes y dictaduras en el continente. ${ }^{92}$

\section{Las poblaciones de Santiago}

Durante los años cincuenta la presencia de católicos y comunistas en los barrios populares siguió fortaleciéndose, así como se fortaleció sus presencias en la política nacional. La Iglesia, que tradicionalmente estaba identificada con el Partido Conservador y las élites, se estaba reorientado hacia posiciones más atentas a la cuestión social, bajo el impulso de figuras como el padre Hurtado o el obispo Manuel Larraín. En 1957 se creó el Partido Demócrata Cristiano (PDC), cuyas posiciones reformistas estuvieron en consonancia tanto con el espíritu del Concilio Vaticano II, como con la alianza para el progreso..$^{93}$ Por otro lado, en 1956 se formó una coalición entre los comunistas, los socialistas y otras formaciones de izquierda, llamada Frente de Acción Popular (FRAP). En estos años, y hasta el golpe de estado, el PDC y los partidos de izquierdas se disputaron el voto de las masas populares, que llegaron a ser fundamentales en las contiendas electorales, también gracias a unas reformas del sistema de voto aprobadas en esos años. ${ }^{94}$ En este contexto, los habitantes de los barrios populares se transformaron en un actor relevante en la vida nacional. ${ }^{95}$

Por un lado, los pobladores fueron robusteciendo sus organizaciones. Los comunistas tuvieron un rol destacado en este aspecto. Entre el 9 y 11 de noviembre de 1951 tomó lugar el Congreso

90 Monseñor Helder Câmara, periódico O Globo, el 7 de enero de 1957.

${ }^{91}$ Luiz Alberto Gómez de Souza, “As várias faces da Igreja Católica”, Estudos Avançados, vo18, n52, 2004, p.77-95.

92 Luiz Alberto Gómez de Souza, "As várias faces da Igreja Católica... op. cit.

${ }_{93}$ Emanuel Giannotti, "Culture catholique et savoir technique au Chili, 1957-1970. L’oeuvre du Hogar de Cristo, la Operación Sitio et le plan de développement de La Reina”, Revue de Histoire Urbaine, 48, 2017, pp. 35-51

94 Sofia Correa, Consuelo Figueroa, Alfredo Jocelyn-Holt, Claudio Rolle, Manuel Vicuña, Historia del siglo XX cbileno: balance paradojal. Santiago, Editorial Sudamericana, 2001. Ricardo Gamboa, "Reformando reglas electorales: La cédula única y los pactos electorales en Chile (1958-1962)."Revista de ciencia politica 31.2 (2011): 159-186. Isabel Torres, La crisis del sistema democrático. Las elecciones presidenciales y los proyectos politicos excluyentes. Chile 1958-1970. Santiago, Editorial Universitaria, 2014.

95 Loyola, Los pobladores... op. cit. 
Constituyente de la Agrupación Provincial de Pobladores de Santiago, mientras el 12 de enero de 1954 se creó la Agrupación Nacional de Pobladores, ambas con claras vinculaciones al Partido. La iniciativa católica en este campo fue más tardía y reducida. Solamente en 1962, en la parroquia Jesús Obrero, se fundó la Central Nacional de Pobladores (CENAPO), con la intención de disputar a los comunistas la influencia en el mundo poblacional. ${ }^{96}$ Sin embargo, durante todos los años cincuenta, la Iglesia estuvo ampliando su labor apostólica en el mundo popular, donde las parroquias incentivaron varias iniciativas, como la formación de Centros de Madres o la constitución de cooperativas de viviendas. ${ }^{97}$ Además de la labor de los párrocos, algunas instituciones católicas comenzaron a trabajar en los barrios populares. Entre ellas, destaca Hogar de Cristo, una fundación benéfica fundada en 1944 por el padre Hurtado sj., que a mitad de los años cincuenta abrió una sección Vivienda. ${ }^{98}$

Por otro lado, en estos años los pobladores precisaron sus demandas y ampliaron su repertorio de acciones. Entre estas, empezaron a destacar las "tomas" de terreno, que surgieron a mitad de los años cincuenta. Si bien las ocupaciones irregulares no eran nuevas, la novedad de las "tomas" fue su carácter organizado, reivindicativo y público. Entre las primeras invasiones con estas características, hubo algunas que tomaron lugar en 1954, protagonizadas por los "agregados" de Nueva La Legua y otros pobladores de la comuna de San Miguel. ${ }^{99}$ Estas acciones recibieron el apoyo de los diputados de izquierda y de las autoridades de la comuna, a guía socialista, pero no es muy claro en qué medida participaron en la organización. Según Orlando Millas, un diputado comunista muy comprometido con los problemas de los pobladores, el Partido participó en la organización de una toma posterior, que se realizó en Puente Alto el 29 de septiembre de 1956.100

La iglesia también suportó estas acciones. Hogar de Cristo y la parroquia Jesús Obrero, en particular el padre Ignacio Vergara sj., entregaron una ayuda fundamental a la población "Gabriela Mistral", surgida la noche del 11 de enero de 1957 con una "toma" de un terreno cercano a Los Nogales. ${ }^{101}$ Debido a los problemas para comprar o expropiar el terreno, se pidió el apoyo del Hogar, que lo adquirió formando una cooperativa entre los pobladores. Los jesuitas ayudaron en los trabajos de consolidación de la población y crearon varios servicios, como una biblioteca, una policlínica y una escuela, en las cuales trabajaron voluntariamente estudiantes, profesionales y visitadoras sociales, organizadas por el Servicio Social del Trabajo de Hogar de Cristo. ${ }^{102}$

Estas "tomas" tuvieron un impacto bastante reducido en la opinión pública. En cambio, la toma de La Victoria provocó una gran conmoción nacional, logrando transformar el problema habitacional de los "sin casa" en una prioridad nacional. ${ }^{103}$ La noche del 30 de octubre de 1957 millares de personas ocuparon un terreno fiscal en el sur de Santiago. Los principales protagonistas de la "toma" fueron los habitantes del Zanjón de la Aguada. La decisión de invadir había sido tomada unos días antes, cuando un incendio destruyó un amplio sector de estos asentamientos precarias. Los partidos de izquierda y la iglesia,

\footnotetext{
96 Ibid.

${ }^{97}$ El diario católico La Voz documenta varias de estas iniciativas, entre las cuales la formación de varias cooperativas. En 1957 el cardinal Raúl Silva Henríquez organizó el Instituto de Viviendas de Cáritas (INVICA), cuya principal misión fue la organización y soporte de cooperativas.

98 Giannotti, "Culture catholique... op. cit.

${ }^{99}$ Las "tomas" tuvieron lugar los días 14 de marzo, 27 de mayo y 2 de diciembre de 1954. Los tres eventos fueron cubiertos por El Siglo. Véase, además: Adrián Escalona, "Comité "agregados de Nueva La Legua" hoy "población Germán Riesco", en Constructores de ciudad, Santiago, SUR, 1989, pp. 36-48

100 Orlando Millas, Memorias 1957-1991. Una digresión. Santiago, CESOC, 1996.

101 Entrevista a Rodrigo Perea, 27.07.2016.

102 "Barrios abandonados contrastan con la opulencia del sector céntrico", La Voz 01.05.1957, p. 2. Dafne Marticorena, Algunas soluciones al problema de las poblaciones callampas, tesis para optar al título de asistente social, escuela Elvira Matte de Cruchaga, Santiago, 1959.

103 Mario Garcés. Tomando su sitio: el movimiento de pobladores de Santiago, 1957-1970. LOM, Santiago 2002.
} 
en particular del Hogar de Cristo, participaron en el cabildo que se realizó después del incendio, se hicieron presente el día de la toma y entregaron apoyo durante la fase de consolidación. ${ }^{104}$

Comunistas e iglesia fueron importantes también en definir la representación de la toma. Los primeros destacaron que los habitantes del Zanjón tomaron la iniciativa de invadir el terreno antes las muchas promesas incumplidas de las instituciones públicas. Celebraron "la heroica lucha de los pobladores", evidenciando que estos reivindicaban "ayuda técnica, no limosnas". ${ }^{105}$ La iglesia, con tonos distintos, también legitimó la acción de los pobladores. Según el padre Lavín, capellán del Hogar de Cristo, antes de la toma los pobladores acudieron a esa institución para pedir ayuda. "Se nos presentó entonces el grave conflicto de que no podíamos apoyar un movimiento ilegal; pero, ante la evidencia de que la indignación colectiva de esa multitud traspasaría cualquier límite, nos esforzamos por temperar y encauzar el movimiento por vías normales." 106 Una misma postura de comprensión y legitimación hacía la acción de los pobladores, se puede encontrar en unos artículos del periódico católico La $V 0 z^{107}$ y en un documental producido en 1958 por Hogar de Cristo y Caritas-Chile. En este, después de mostrar las condiciones de vida en las poblaciones "callampas" y las dramáticas escenas del incendio ocurrido en el Zanjón, se presentaba la toma como "un movimiento pacífico donde todos unidos trabajan por un mínimo de bienestar". 108

Los relatos construidos por comunistas e iglesia no eran muy disimiles. Sin embargo, a pesar de intenciones parecidas, en la naciente población surgió un conflicto para la hegemonía. La obra de los voluntarios de Hogar de Cristo, guiados por el padre Del Corro sj., creó varios roces con la directiva comunista, dando pie a acusaciones reciprocas. ${ }^{109}$. La situación fue particularmente tensa durante 1958, sobre todo cuando Del Corro formó un Comité Renovado para disputar el liderazgo al Comité Central, en el cual primaban los militantes comunistas. El domingo 22 de junio se llegó a un enfrentamiento con algunos heridos, causado por una divergencia respecto al uso de unos sitios en la población. ${ }^{110}$ La prensa comunista acusó Del Corro de sembrar divisionismo, ${ }^{111}$ mientras una visitadora social católica culpó los comunistas de tener fines políticos y de provocar la división y la desconfianza. ${ }^{112}$ En los años siguientes, los comunistas mantuvieron el control de la directiva, con la participación de los socialistas. ${ }^{113}$ La iglesia siguió operando en la población, aparentemente sin que se produjeran conflictos. ${ }^{114}$

104 Espinoza, Para una historia... op. cit. Garcés, Tomando su... op. cit. Alexis Cortés, "El movimiento de pobladores chilenos y la población La Victoria: ejemplaridad, movimientos sociales y el derecho a la ciudad." EURE 40:119, 2014, pp. 239-260. Emanuel Giannotti, "Una ciudad de propietarios. El caso de la Población La Victoria", AUS 15, 2014, pp. 40-45

105 Ver los artículos aparecidos en El Siglo durante los días y meses posteriores a la toma. Además, véase el periódico La voz de la Victoria. Órgano oficial del Comité Central. El primer número fue publicado el 16 de noviembre de 1958, y se siguió publicado para todo el año sucesivo.

106 Álvaro Lavín, "El trabajo del Hogar en las poblaciones" (memorándum, 8 de mayo de 1958), en Mensaje, n.443, 1995. p.108. 107 El número 85 de La Voz, publicado en enero de 1958, titulaba en la portada: "Población La Feria es una esperanza y una responsabilidad para todo Chile"

108 "Las Callampas" documental realizado por el Instituto Fílmico UC, y producido por Hogar de Cristo y Caritas-Chile, 1958. Dirección: Rafael Sánchez sj.; texto: Raúl Aicardi. http://archivofilmico.uc.cl/archivo/las-callampas/

109 Véase para los comunistas: La voz de la Victoria. Órgano oficial del Comité Central. Para los católicos: Hilda Sotomayor, Fisionomía y valores de una población callampa, memoria para optar al título de asistente social, Escuela "Elvira Matte de Cruchaga", Santiago, 1958. Alvaro Barros, Juan y La Victoria, Santiago, Mistral, 1978

110 "Rebelión de pobladores: luchan en las calles del campamento "La Victoria” de San Joaquín”, El Clarín, 24.06.1957, p.8

111 "Pretenden encender guerra civil entre los pobladores", El Siglo, 25.06.1957, p. 2. "Facciosos serán derrotados", El Siglo, 27.06.1958, p. 3

112 Sotomayor, Fisionomía y valores... op. cit.

113 Gerald Clark, The coming explosion in Latin America, 1962, McKay, New York, pp. 215 y sgg. Antonio Bentué, Religión y marginalidad social en la población La Victoria de Santiago (Chile). Tesis de doctorado, Facultad de Teología Protestante, Strasourg, 1972, pp. 45 y sgg.

114 Los relatos de los pobladores tienden a destacar la unidad, más bien que los conflictos internos. Véase: Grupo Salud Poblacional y Manuel Paiva, 1989, Pasado: victoria del presente, Talleres Vicaria Zona Oeste. Juan Lemuñir, 1990, Crónicas de la Victoria. Testimonios de un poblador, Ediciones documentas; Carlos Morales, La Victoria de Chile, editorial Llama, s.f. Grupo de Identidad Popular, 2003, Memorias de la victoria. Grupo de trabajo de La Victoria, 2007, La Victoria. Rescatando su historia, Editorial Arcis 
A partir de estos años, la Iglesia comenzó a manifestar una creciente preocupación para la penetración comunista en el mundo poblacional. Un informe sobre el trabajo de Hogar de Cristo, publicado en 1959, dedicaba un capítulo a este tema. "La experiencia de dos años autoriza a señalar al marxismo como al principal enemigo de los pobladores." Se denunciaba la "labor proselitista hábilmente organizada y dirigida" por los marxistas, y se constataba que la acción cristiana no supo fructificar "en la vida de sus hermanos pobres." Para tal fin, se planteaba la necesidad de superar las acciones aisladas de beneficencia y caridad, para iniciar un trabajo apostólico organizado e integrado dentro de las poblaciones. Las acciones esporádicas a poco servían, era preciso vivir junto a los pobladores y trabajar codo a codo con ellos. A través del trabajo, se creaba amistad e igualdad, permitiendo la integración de las clases sociales. ${ }^{115}$

El 22 de julio de 1961 se produjo otra "toma” masiva, también liderada por comunistas. ${ }^{116}$ La iglesia justificó los ocupantes, movidos por la desesperación de no tener un lugar donde ampararse, pero culpó los comunistas, porque se aprovecharon de la miseria humana.117 Los invasores lograron un acuerdo con el gobierno, y fueron trasladados a un terreno más periférico. Allí se levantó la población San Rafael, en la cual, paralelamente al Comando Central de Pobladores, liderados por los comunistas, surgió un Comité Independiente. ${ }^{118}$ La tensión salió, hasta que en septiembre de 1961, los estudiantes universitarios, sobre todo católicos, que estaban trabajando para ayudar los pobladores, denunciaron amenazas y agresiones. ${ }^{119}$ Según El Siglo, eran más bien los "sectores más reaccionarios del catolicismo nacional" que socavaban "las bases unitarias del movimiento de los trabajadores", con la excusa de la "ayuda". ${ }^{120} \mathrm{El}$ enfrentamiento, que llegó a ser violentos en varias ocasiones, perduró unas semanas. Los principales diarios nacionales alimentaron la tensión, con titulares como: "Jóvenes democristianos llevaron guerra fría a la población San Rafael", 121 "Una dictadura comunista hay en San Rafael", 122 "Nido de Ratas en S. Rafael". ${ }^{123}$ En el cuerpo de este último artículo se podía leer: "En la Población San Rafael, hay atmósfera de miedo. Es un Berlín chico."

Meses después, Leonardo Cáceres, en un artículo publicado por Mensaje describía una geografía de barrios populares en los cuales luchaban "Ideologías opuestas" y denunciaba la penetración comunista en poblaciones como La Victoria, La Legua, San Rafael, Los Nogales, La Palma y la José María Caro. Según quien escribía, la acción de los comunistas tenía solamente fines políticos y había producido el descontento de muchos pobladores. Se citaba un poblador de La Victoria, según el cual "estamos detrás de la cortina de hierro." Sin embargo, en las mismas poblaciones operaban grupos católicos, que representaban "un sólido dique" contra las fuerzas comunistas. "Aunque el esfuerzo es todavía de muy pequeño alcance y presenta serias limitaciones, puede significar en el futuro un camino con consecuencias de un valor imprevisible". ${ }^{24}$

Efectivamente, en los años siguientes, la Democracia Cristiana logró captar el voto de los pobladores, que fueron importantes para la victoria de Eduardo Frei Montalva en 1964. ${ }^{125}$ Durante la

\footnotetext{
115 Un extracto del Informe fue publicado por la revista Mensaje ( $\mathrm{n}^{\circ} 78$, mayo de 1959) y por el periódico La Voz ( $\mathrm{n}^{\circ} 112$, 01.03.1959). Además, véase la entrevista a Josse Van der Rest en el mismo número de La Voz. El padre jesuita Van der Rest llegó a Chile en 1957 y, durante los años sesenta, tuvo un lugar destacado en Hogar de Cristo - Vivienda.

116 Se trataba de la toma conocida con el nombre de Santa Adriana. Véase: Garcés, Tomando su sitio...op. cit.

117 Javier Rojas, “La invasión de los Sin Tierra”, La Voz 30.07.1961. “La invasión de Santa Adriana”, La Voz, 06.08.1961.

118 Leonardo Cáceres, "El penoso invierno de San Rafael”, La Voz, 01.07.1962

119 "Persecución comunista obligó a universitarios a suspender su ayuda a familias de San Rafael”, El Mercurio, 21.09.1961, p.15

120 "Provocación en San Rafael”, El Siglo, 22.09.1961, p. 2

121 "Jóvenes democristianos llevaron guerra fría a la población San Rafael", Las Últimas Noticias, 22.09.1961, p. 3

122 "Una dictadura comunista hay en San Rafael", El Diario Ilustrado, 27.09.1961, p. 4

123 "Nido de ratas en S. Rafael", Las Últimas Noticias, 08.11.1961, p. 3

124 Leonardo Cáceres, 1962, "Las callampas, un territorio inédito”, Mensaje 109, pp. 240-243

125 Carmelo Furci, El Partido Comunista de Chile y la vía al socialismo, Santiago, Ariadna, 2008.
} 
campaña electoral, varios folletos y discursos fueron dirigidos a este sector de la población. ${ }^{26}$ Anteriormente, el centro para el Desarrollo Económico y Social de América Latina (DESAL), fundado por el padre jesuita Roger Vekemas, había comenzado a estudiar las poblaciones "marginales", 127 y planteó un programa de reformas para integrar sus habitantes a la vida nacional, conocido como "Promoción Popular". ${ }^{128}$ Una vez al gobierno, Frei promovió estas reformas, aunque se pudieron implementar solamente en parte, debido a una fuerte resistencia de las oposiciones. ${ }^{129}$ Paralelamente, se puso en marcha una política de vivienda dirigida principalmente a los sectores populares, cuyo programa más emblemático fue la Operación Sitio. ${ }^{130}$

Los años entre el triunfo de la revolución cubana y la crisis de los misiles, fueron uno de los momentos de mayor tensión de la guerra fría en América Latina, y fueron un momento de duro conflicto también en las poblaciones de Santiago. La confrontación entre católicos y comunistas continuó en los años sucesivos, sin embargo, se produjeron también inesperadas convergencias. El movimiento de la iglesia joven, que se formó a raíz de la toma de la catedral de Santiago en 1968, o la participación de católicos en la coalición de izquierda que ganará las elecciones de 1970, testimonian este acercamiento, que se producirá también en las poblaciones, y que será aún más estricto durante los años de la dictadura militar. ${ }^{131}$ Sin lugar a duda, la labor de ambos, si bien conflictiva en ciertos momentos, contribuyó a mejorar las condiciones de vida de los barrios populares, y a integrar sus habitantes en la vida social y política del país.

\section{Conclusiones}

A pesar de que los estudios citados en la introducción, sobre la politización de los barrios populares durante los años sesenta, coincidían en descartar actitudes revolucionarias, sí se mostraban algunas diferencias. En los contextos en los cuales los habitantes de estos barrios tenían un mayor apoyo político y social, se había notado más integración y participación política. ${ }^{132}$

Creemos que esto se confirma mirando los casos de Río y Santiago en los años cuarenta y cincuenta. El marxismo y el catolicismo, sin duda, operaron en los barrios populares de acuerdo a ideologías muy distintas, los primeros fomentando la lucha para conquistar derechos, los segundos poniendo énfasis en la paz social, muchas veces con una actitud paternalista, que bien se expresó en las prácticas del trabajo social y de la acción apostólica. Además, había claros intentos de proselitismo político, que generaron roces y a veces conflictos abiertos entre iglesia y partidos de izquierda. Sin embargo, es interesante notar que la actuación de los comunistas y de los católicos terminó convergiendo en varios temas comunes. En primer lugar, ambos sustentaron la lucha de los favelados y los pobladores para una residencia estable. En Río, la Fundación Léon XIII fue muy criticada por su actuación que

126 “Todo Chile bajo un techo. El problema de las poblaciones. Lo que hará el gobierno de Frei”, folleto 1964. "Mi compadre e yo", folleto 1964. "A los pobladores. Discruso del presidente nacional de la Democracia Cristiana, diputado R. Fuentealba, ${ }^{\circ}$ de Mayo - 1964", folleto 1964.

127 DESAL - IDE, Informe sobre poblaciones marginales, Santiago, 1963. DESAL, Poblaciones marginales y desarrollo urbano. El caso chileno, Santiago, 1965

128 DESAL, América Latina y desarrollo social, Santiago 1966. DESAL - CEDEP, Aportes para un programa de Promoción Popular, Santiago, 1966. Además, veáse los números especiales de la revista Mensaje editados por Vekemans: "Revolución en Amércia Latina. Visión cristiana." No 115, diciembre de 1962; "Reformas revolucionarias en América Latina. Visión cristiana", n” 123 , octubre de 1963.

129 Daniela Oñate, La politica de "promoción popular" gobierno de Eduardo Frei Montalva (1964-1970), Tesis para optar al grado de licenciatura en historia, Santiago, Universidad Andrés Bello, 2010.

130 Giannotti, "Culture catholique... op. cit.

131 Élodie Giraudier, "Los católicos y la política en Chile en la segunda mitad del siglo XX” in Revista del CESLA 18, 2015, pp. 213-237. Maximiliano Salinas, "La recherche d'un lieu sacré: la trajectoire sociale et religieuse des pobladores au Chili (19621992)", Social Compass 43:3, 1996, pp. 353-366

132 Goldrich, Pratt y Schuller, “The political... op. cit. Handelman, “The political... op. cit. 
indirectamente consolidaba las favelas de la ciudad, ${ }^{133}$ mientras que la Cruzada San Sebastián también actuó para mejorar y consolidar muchas favelas. Símilmente, las instituciones de inspiración comunista siempre han defendido los derechos de los favelados a permanecer en sus lugares de residencia. En Santiago, podemos notar un mismo apoyo a la consolidación de varios barrios populares, incluso cuando estos se formaron a través de "tomas" de terreno. Al respecto, es muy emblemático el caso de la población La Victoria, en donde la acción de los pobladores fue suportada tanto por los comunistas, como por los católicos. A pesar de algunos roces y conflictos iniciales, en los años siguientes ambos trabajaron en conjunto para apoyar el desarrollo de esta población.

En segundo lugar, católicos y comunistas entendieron que la lucha por la permanencia pasaba por el derecho a la propiedad de la tierra. Según el congresista católico Cardoso de Menezes, todos deberían ser propietarios: "el trabajador brasileño no es un comunista, no quiere matar a nadie, no quiere dinamitar nada. Él desea tener una pequeña casa, pero suya". ${ }^{134}$ Por otro lado, las instituciones cercanas a los comunistas, como la UTF, también defendieron abiertamente el acceso a la propiedad privada. El artículo $3^{\circ}$ del anteproyecto de ley de los trabajadores favelados propuesto por Magarinos Torres defendía la expropiación de las tierras donde estaban las favelas para transferir la propiedad a los ocupantes. ${ }^{135}$ Lo mismo se puede evidenciar en el caso chileno. Los católicos, de acuerdo a las encíclicas sociales, defendieron abiertamente la necesidad de dar una casa o un terreno en propiedad a cada familia. Instituciones como Hogar de Cristo y programas emblemáticos de la Democracia Cristiana, como la Operación Sitio, tuvieron el objetivo explícito de democratizar la propiedad. ${ }^{136}$ Los comunistas, si bien lucharon contra la propiedad privada de los medios de producción, no dudaron en apoyar la demanda de los pobladores de tener un lugar proprio en el cual vivir, como claramente planteado por Orlando Millas en sus memorias. ${ }^{137}$ Por lo tanto, no extraña que uno de los principales objetivos de los programas habitacionales chilenos, bajo cualquier gobierno, fue la creación de propietarios. ${ }^{138}$

En tercer lugar, el trabajo cotidiano de católicos y comunistas, fue fundamental para mirar los barrios populares desde perspectivas distintas, llevando a la construcción de nuevas teorías y reflexiones. Se rechazó la visión de los habitantes como marginales o como lumpen, evidenciando que, en realidad, estos barrios eran parte de la ciudad, y sus habitantes tenían la aspiración de integrarse en la sociedad. El reconocimiento y el apoyo de estas aspiraciones será muy importante para generar un efectivo proceso de integración, por cierto, parcial e incompleto, pero que existió, siendo sucesivamente truncado por las dictaduras y las reformas neoliberales, las cuales contribuyeron a segregar y estigmatizar estos lugares.

En este sentido, la colaboración de la iglesia con los militantes de izquierda durante las dictaduras, no se generó desde un vacío, sino que se fundó en la experiencia acumulada durante los años cuarenta, cincuenta y sesenta. Este trabajo abrió nuevos caminos y generó inesperadas convergencias, entre una Iglesia que volvió a ser preocupada por los pobres, y un Partido Comunista que, además de las fábricas, comenzó a poner atención a los barrios populares.

\footnotetext{
133 Rafael Soares Gonçalves, Favelas do Rio de Janeiro..., op. cit.

134 APERJ, Colección DPS, código n 1046.

135 Rafael Soares Gonçalves, Favelas do Rio de Janeiro... op. cit., p.175.

136 Giannotti, "Culture catholique... op. cit.

137 Millas, Memorias... op. cit. Giannotti, Una ciudad de... op. cit.

138 Emanuel Giannotti y Hugo Mondragón, "La inestabilidad de la forma. Proyectos para barrios populares en Santiago de Chile, 1953-1970”, Bitácora Urbano-Territorial, 2017, 27:1, pp. 35-46.
} 